$06.1 ; 07.2$

\title{
Особенности вольт-амперных характеристик полевых транзисторов с активными слоями на основе композитных пленок полупроводниковых полимеров с наночастицами неорганических перовскитов
}

\author{
(C) Е.В. Остроумова, А.Н. Алешин \\ Физико-технический институт им. А.Ф. Иоффе РАН, Санкт-Петербург, Россия \\ ๑E-mail: aleshin@transport.ioffe.ru \\ Поступило в Редакцию 14 июня 2019г. \\ В окончательной редакции 14 июня 2019г. \\ Принято к публикации 4 сентября 2019 г.
}

\begin{abstract}
Проведен анализ вольт-амперных характеристик композитных полевых транзисторов с активными слоями на основе неорганических перовскитов - нанокристаллов галогенидов цезия $\mathrm{CsPbr}_{3}$, внедренных в матрицу полупроводникового полимера $\mathrm{PFO}\left(\mathrm{PFO}: \mathrm{CsPBr}_{3}\right)$. Обнаружен и объяснен рост коэффициента усиления по току $\beta$ в вольт-амперных характеристиках таких структур с ростом отрицательного напряжения на затворе. Показано, что при наличии дополнительной инжекции неосновных носителей из электродов в канал транзистора возможно создание композитных светоизлучающих полевых транзисторов с улучшенными характеристиками.
\end{abstract}

Ключевые слова: проводящие полимеры, нанокристаллы перовскитов, полевые транзисторы.

DOI: 10.21883/PJTF.2019.23.48720.17929

Новые материалы на основе нанокристаллов (НК) неорганических перовскитов $\operatorname{CsPb}\{X\}_{3}$, где $X=\mathrm{Cl}, \mathrm{Br}$ или I, демонстрируют уникальные оптические и электрические свойства, такие как возможность эффективного поглощения и эмиссии излучения в широком диапазоне энергий, большие времена жизни носителей заряда и их высокая подвижность [1]. При этом важно отметить, что солнечные элементы на основе металлоорганических галогенидных перовскитов обладают очень высокой эффективностью преобразования солнечной энергии (power conversion efficiency) $\sim 24.2 \%$ (май 2019 г.) [2], что привлекает к ним огромное внимание в мире.

Недавно в наших работах была исследована возможность создания гибридных полевых транзисторов (ПТ, FET) с активными слоями на основе НК неорганических перовскитов - галогенидов цезия $\mathrm{CsPbBr}_{3}\left(\mathrm{CsPbI}_{3}\right)$, внедренных в матрицу полупроводникового сопряженного полимера - полифлуорена (PFO) (PFO: $\mathrm{CsPbr}_{3}$ $\left.\left(\mathrm{CsPbI}_{3}\right)\right)[3,4]$. Согласно данным просвечивающей электронной микроскопии и просвечивающей электронной микроскопии высокого разрешения, монодисперсные НК $\mathrm{CsPbBr}_{3}$ имели кубическую форму, определяемую кристаллической структурой перовскита, а их средний размер составил 8-10 nm [4]. В качестве подложки был использован кремний $n$-типа с изолирующим слоем $\mathrm{SiO}_{2}$ с нанесенными вакуумным напылением контактами $\mathrm{Au}$ и $\mathrm{Al}$ (исток-сток), при этом толщина слоя $\mathrm{SiO}_{2}$ по всей площади, в том числе и под контактами, составляла $\sim 200 \mathrm{~nm}$. Расстояние между $\mathrm{Au}-$ и Al-контактами составляло $7 \mu \mathrm{m}$ при ширине контактов $1 \mathrm{~mm}$. Раствор сопряженного полимера PFO в толуоле с нанокристаллами галогенидов цезия $\mathrm{CsPbBr}_{3}$ в coотношении компонентов 1:1 наносился на подложку с контактами методами полива или центрифугирования. На рис. 1, $a$ приведена схематическая структура полевого транзистора с композитной пленкой на основе полимера PFO с неорганическими наночастицами $\mathrm{CsPbBr}_{3}$ [4]. Исследуемая структура (рис. 1,a) имеет вид полупроводникового МДП-транзистора (МДП металл-диэлектрик-полупроводник) с индуцированным (наведенным) каналом. Выходные и передаточные вольт-амперные характеристики (BAX) ПТ на основе пленок $\mathrm{PFO}: \mathrm{CsPBBr}_{3}$ измерялись в атмосфере азота в темноте при температурах 100-300 K с использованием азотного оптического криостата optCRYO198 c функцией стабилизации температуры и электронной автоматизированной измерительной системы на основе пикоамперметра Keithley 6487 и программируемого источника напряжения AKIP-1124. На рис. 1, b, $c$ представлены выходные ВАХ композитных (полимер PFO-НК $\left.\mathrm{CsPbBr}_{3}\right)$ ПТ, измеренные при температурах 250 и $100 \mathrm{~K}$ соответственно. Как следует из ВАХ, представленных на рис. $1, b, c$, в исследованных ПТ-структурах наблюдается значительный рост коэффициента усиления по току $\beta$ с ростом отрицательного напряжения на затворе $V_{\mathrm{G}}$ от 0 до $-6 \mathrm{~V}$. Аналогичные особенности наблюдались и в BAX композитных ПТ с активными слоями на основе PFO с другими неорганическими перовскитными $\mathrm{HK}-\mathrm{CsPbI}_{3}\left(\mathrm{PFO}: \mathrm{CsPb}_{3}\right)$ [3]. Однако эти особенности BAX композитных ПТ не были детально объяснены в предыдущих работах. 

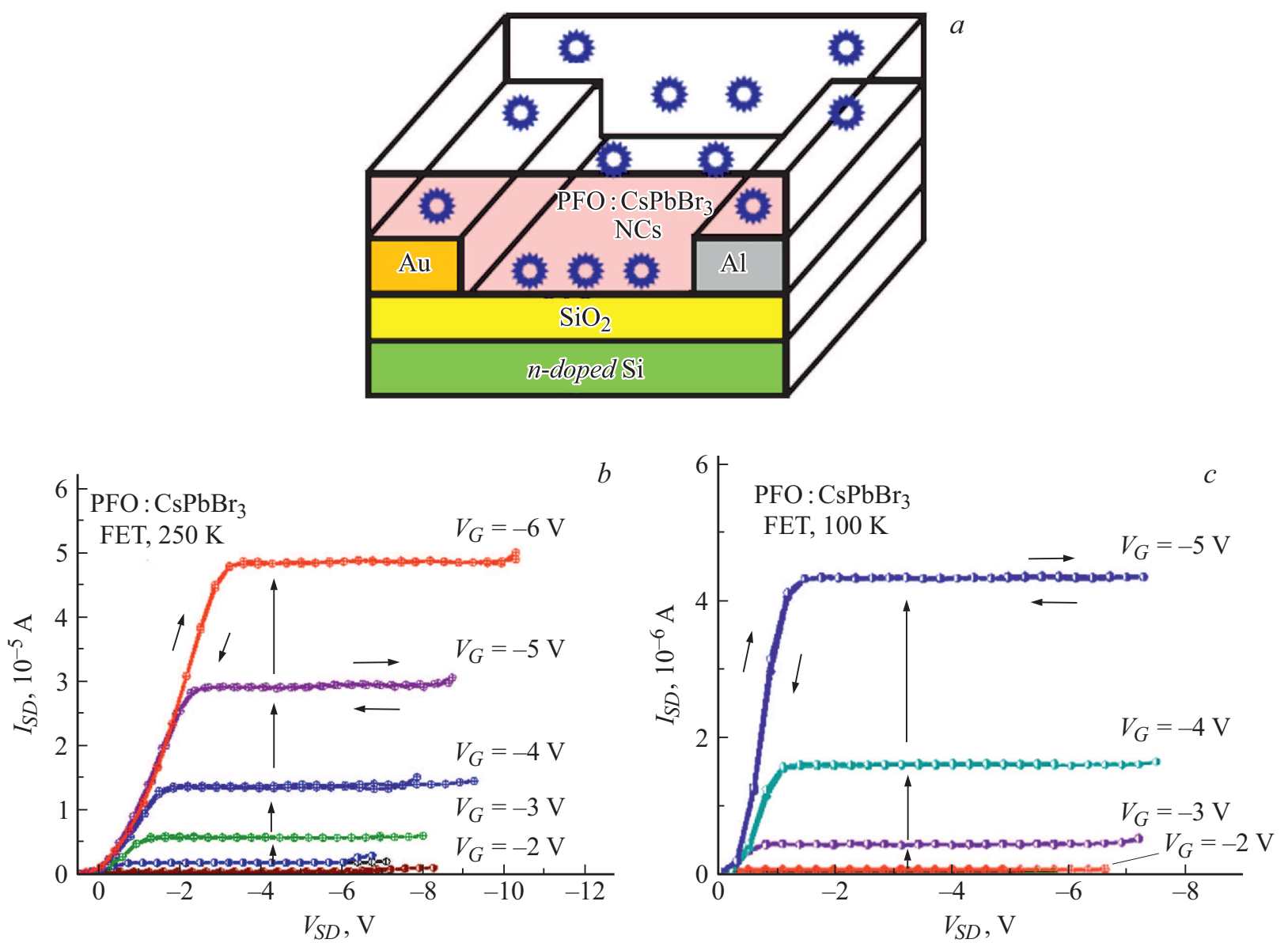

Рис. 1. $a$ - структура ПТ на основе композитной пленки, состоящей из $\mathrm{HK} \mathrm{CsPbr}_{3}$, внедренных в матрицу полупроводникового полимера PFO (PFO: $\left.\mathrm{CsPBr}_{3}\right) . b$ и $c-$ выходные вольт-амперные характеристики ПТ $\mathrm{PFO}: \mathrm{CsPbr}_{3}(1: 1)$, измеренные в темноте при температурах $250(b)$ и $100 \mathrm{~K}(c)$ при различных отрицательных напряжениях на затворе $V_{G}$. Нижние кривые на части $b$ соответствуют напряжению на затворе -1 и $0 \mathrm{~V}$. Вертикальными стрелками показаны темпы роста коэффициента усиления $\beta$ при линейном увеличении отрицательного напряжения на затворе $V_{G}$. Наклонные и горизонтальные стрелки указывают на отсутствие гистерезиса ВАХ при увеличении и уменьшении напряжения между истоком и стоком.

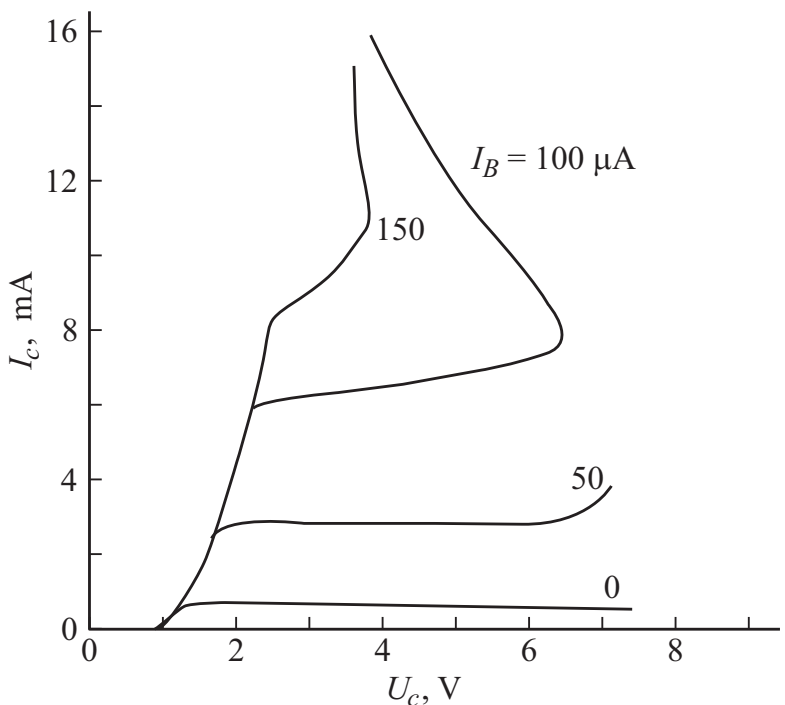

Рис. 2. Экспериментальные вольт-амперные характеристики - коллекторные характеристики $S$-типа в оже-транзисторе на основе $n$ - $\mathrm{Si}-\mathrm{SiO}_{2}-\mathrm{Al}$ в схеме с общим эмиттером при $T=300 \mathrm{~K}, \alpha \geqslant 1[6]$.
На наш взгляд, наблюдаемые особенности вольтамперных характеристик ПТ на основе пленок PFO: $\mathrm{CsPbBr}_{3}(1: 1)$ по аналогии с полупроводниковыми туннельными МДП-транзисторами (рис. 2) могут свидетельствовать о том, что при определенных условиях в объем канала полевого транзистора поступают дополнительные неравновесные носители тока, т.е. происходит инжекция неосновных носителей тока в канал ПТ. В биполярных полупроводниковых транзисторах, включенных в схеме с общей базой, коэффициент усиления по току $\beta$ связан с другим коэффициентом усиления для транзисторов $\alpha$ соотношением [5]:

$$
\beta=\frac{I_{c}}{I_{e}}=\frac{\alpha}{1-\alpha}
$$

где $I_{c}$ и $I_{e}-$ коллекторный и эмиттерный токи соответственно, а $\alpha=\alpha_{0}$ - коэффициент усиления транзистора по току в схеме с общим эмиттером. В идеальном случае в биполярных транзисторах коэффициент усиления $\alpha_{0}$ может достигать единицы. Но когда есть дополнительная 


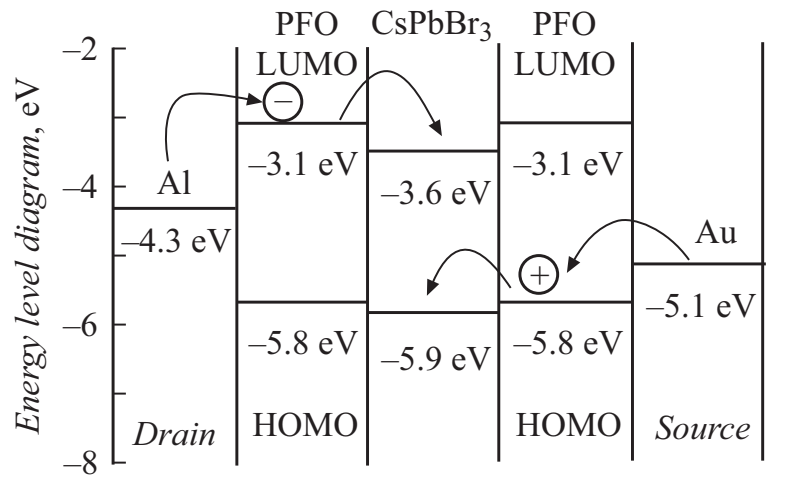

$a$

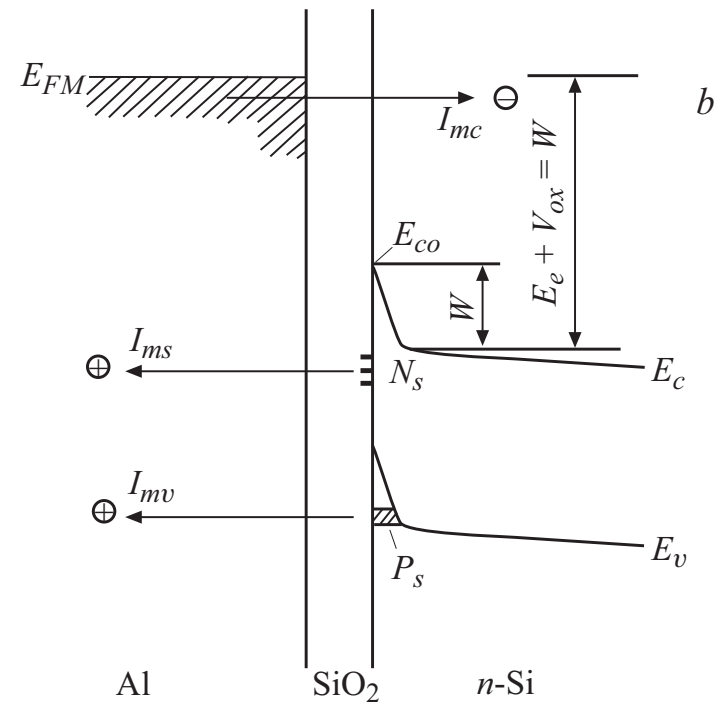

Pис. 3. $a$ - зонная диаграмма структуры $\mathrm{Al} / \mathrm{PFO} / \mathrm{CsPbr}_{3} / \mathrm{Au} ; b-$ барьер Шоттки и токи инжекции в структурах $\mathrm{MДП} \mathrm{с}$ индуцированным квантовым колодцем на границе раздела металл-диэлектрик $[5,6]$.

инжекция неравновесных носителей в объем, коэффициент усиления может превысить единицу, поэтому в данном случае следует ввести дополнительный коэффициент $A \geqslant 0$, связанный с инжекцией неравновесных электронов (или дырок). Тогда в соотношение (1) необходимо подставить суммарный коэффициент усиления $A \alpha_{0} \geqslant 1$, и коэффициент усиления тока $\beta$ будет связан с коэффициентом усиления тока в схеме с общим эмиттером $\alpha$ соотношением:

$$
\beta=\frac{I_{c}}{I_{e}}=\frac{I_{c}+A I_{c}}{I_{e}-\left(I_{c}+A I_{c}\right)}=\frac{\alpha+A \alpha}{1-(\alpha+A \alpha)} .
$$

При $A=0$ (в случае отсутствия дополнительной инжекции) рост коллекторного тока $I_{c}$ пропорционален увеличению напряжения на базе. Однако при $A>0$ ток может нарастать непропорционально быстро с увеличением поданного на базу транзистора напряжения, как это было рассчитано и экспериментально показано в работе [6] на примере BAX туннельных МДП-транзисторов на основе $n-\mathrm{Si}-\mathrm{SiO}_{2}-\mathrm{Al}$ с туннельно-тонким слоем диэлектрика. На рис. 2 приведены экспериментальные выходные ВАХ оже-транзистора в схеме с общим эмиттером для структуры $n$-Si- $\mathrm{SiO}_{2}-\mathrm{Al}$ с туннельно-проницаемым слоем окисла [6]. Как видно из этих данных, при наличии дополнительного источника неосновных носителей в том случае, когда $\alpha \geqslant 1$, возможно появление нестабильностей тока вплоть до эффекта переключения.

На ВАХ полевых МДП-транзисторов с активными слоями, выполненными на основе проводящих полимеров и неорганических нанокристаллов перовскитов, представленных на рис. $1, b, c$, хорошо виден рост коэффициента усиления $\beta$ для тока $I_{S D}$ (ток между контактами $\mathrm{Au}$ и $\mathrm{Al}$ - исток-сток) с ростом отрицательного напряжения на затворе $V_{G}$ (аналог базы биполярного транзистора). На рис. 3, $a$ представлена энергетическая зонная диаграмма структуры $\mathrm{Al} / \mathrm{PFO} / \mathrm{CsPbBr}_{3}(\mathrm{HK}) / \mathrm{Au}$ в равновесном состоянии. Ширина запрещенной зоны полимера $\mathrm{PFO}$ составляет $E_{g} \sim 2.7 \mathrm{eV}$, тогда как перовскитные наночастицы $\mathrm{CsPbBr}_{3}$ имеют ширину запрещенной зоны $E_{g} \sim 2.3 \mathrm{eV}$, при этом атомы Cs в перовскитных НК находятся в ионизованном состоянии. В отличие от полупроводниковых планарных транзисторов в нашем случае контакты исток-сток выполнены из разных металлов: золото и алюминий.

В исследуемом композитном (полимер-НК перовскита) ПТ слой $n-\mathrm{Si}-\mathrm{SiO}_{2}$ (база транзистора) является затвором, который управляет индуцированным слоем объемного заряда на границе $\mathrm{SiO}_{2}$-полимер PFO. $V_{G}-$ это напряжение, приложенное к затвору, а $I_{S D}$ и $V_{S D}$ - ток и напряжение между контактами $\mathrm{Au}-\mathrm{Al}$ (исток-сток), аналоги коллекторного тока и напряжения на коллекторе. C ростом отрицательного напряжения на базе $V_{\mathrm{G}}$ (от 0 до $-6 \mathrm{~V}$ ) на границе раздела (интерфейсе) $\mathrm{SiO}_{2}-\mathrm{PFO}: \mathrm{CsPbBr}_{3}$ в полимере PFO электрическим полем индуцируется канал проводимости с положительным зарядом. В этом случае контакты металл $(\mathrm{Au}, \mathrm{Al})$-полимер (PFO) в ПТ можно рассматривать как поверхностные барьеры Шоттки с индуцированным промежуточным слоем диэлектрика, которые будут смещены по-разному: для Al это прямое смещение, а для $\mathrm{Au}$ - обратное (рис. 3,b). Инжекция носителей заряда (электронов) будет идти из Al в „зону проводимости“ - LUMO (lowest unoccupied molecular orbital) - полимера, и чем больше смещение, тем меньше эффективная толщина потенциального барьера металл-полимер, а вероятность туннелирования носителей заряда (электронов) сквозь барьер значительно возрастает с ростом отрицательного напряжения на затворе. Инжектированные из стока-истока носители заряда могут излучательно рекомбинировать в простран- 
ственной области между электродами ПТ, при этом реализуются основные преимущества светоизлучающих ПТ - способность к переключению и эмиссии света, совмещенные в одном приборе $[3,4]$.

Проведен анализ ВАХ гибридных полевых транзисторов с активными слоями на основе $\mathrm{PFO}: \mathrm{CsPbr}_{3}$. Объяснен рост коэффициента усиления по току $\beta$ в $\mathrm{BAX}$ таких структур с ростом отрицательного напряжения на затворе. Показано, что при дополнительной инжекции неосновных носителей из металлических контактов в объем композитного (полимер $\mathrm{PFO}-\mathrm{HK} \mathrm{CsPbr}_{3}$ ) ПТ возможно создание композитных и светоизлучающих ПТ с улучшенными характеристиками.

\section{Финансирование работы}

Работа выполнена при поддержке программы Президиума РАН № 5 ,Фотонные технологии в зондировании неоднородных сред и биообъектов“.

\section{Конфликт интересов}

Авторы заявляют, что у них нет конфликта интересов.

\section{Список литературы}

[1] Ono L.K., Qi Y. // J. Phys. D. 2018. V. 51. N 9. P. 093001 $(1-27)$.

[2] National Renewable Energy Laboratory. Best Research Cell Efficiencies [Электронный pecypc]. Режим доступа: www.nrel.gov/ncpv/images/efficiency_chart.jpg (дата обращения: май 2019).

[3] Aleshin A.N., Shcherbakov I.P., Gushchina E.V., Matyushkin L.B., Moshnikov V.A. // Organic Electron. 2017. V. 50. N 1. P. 213-219.

[4] Алешин А.Н., Щербаков И.П., Кириленко Д.А., Матюшкин Л.Б., Мошников В.А. // ФТТ. 2019. Т. 61. В. 2. С. 388 394.

[5] Зи С. Физика полупроводниковых приборов. М.: Мир, 1984. Кн. 2. $456 \mathrm{c}$.

[6] Остроумова Е.В., Рогачев А.А. // ФТП. 1994. Т. 28. В. 8. C. 1411-1423. 